\title{
Pattern of Organisms and Antibiotics Used in Treating Diabetes Foot Infection
}

\author{
Joehaimey $\mathrm{J}^{\mathrm{a}}$, Mohamad Adam B ${ }^{\mathrm{b}}$, M Anwar Hau $\mathrm{A}^{\mathrm{a}}$, Kamil MK ${ }^{\mathrm{c}}$, SP Jaya Purany ${ }^{\mathrm{d}}$, Saadon $\mathrm{I}^{\mathrm{e}}$, Chee Huan $\mathrm{P}^{\mathrm{f}}$, \\ Azura $\mathrm{H}^{\mathrm{g}}$
}

\author{
${ }^{a}$ Orthopaedic Department, Hospital Raja Perempuan Zainab II, Kota Bahru, Kelantan. \\ ${ }^{b}$ Biostatistics Unit, Clinical Research Center, Kuala Lumpur. \\ 'Orthopaedic Department, Hospital Tengku Ampuan Rahimah, Klang, Selangor. \\ ${ }^{d}$ Patient Registry Unit, Clinical Research Center, Kuala Lumpur. \\ e Orthopaedic Department, Hospital Sultan Ismail, Johor. \\ ${ }^{f}$ Orthopaedic Department, Hospital Sultanah Bahiyah, Alor Setar. \\ ${ }^{3}$ Hospital Raja Perempuan Zainab II, Kota Bahru, Kelantan.
}

\begin{abstract}
Introduction: The aim of this study is to determine the most common organisms isolated in diabetic foot infection and the most utilised antibiotic regimes as the first line of treatment. Methods: This is a retrospective record review of the National Orthopaedic Registry Malaysia among diabetes mellitus type 2 patients who had foot infections. All identified cases admitted to 18 government hospitals in Malaysia from the $1^{\text {st }}$ January 2008 until the $31^{\text {st }}$ December, 2009 were included in the study. Results: A total of 416 patients were included in the study. The most common organisms cultured were Proteus species (17.5\%), Klebsiella species (17.1\%) and Staphylococcus aureus (17.9\%), while the most commonly used antibiotic was ampicillin/sulbactam (67.5\%). None of the patients was appropriately treated with metronidazole, cefoperazone or fucidic acid. All patients were given appropriate antibiotics to treat Serratia infection. Conclusion: Significant number of patients with diabetic foot infections were not treated using appropriate antibiotics as the first line treatment.
\end{abstract}

\section{KEYWORDS: Antibiotics, Diabetes Mellitus, Diabetes Complications, Foot Ulcer}

\section{INTRODUCTION}

Foot infections are a common and serious problem in diabetic patients. Foot infection in patients with diabetes cause substantial morbidity with frequent visits to health care professionals. If inadequately managed, it may lead to amputation of lower extremities. They usually occur as a consequence of skin ulceration, which initially is colonized with normal flora, and later infected with pathogens. Infection is defined clinically by evidence of inflammation, and appropriate cultures can determine the microbial aetiology. ${ }^{1}$

Foot infection in diabetic patients can accelerate dramatically with devastating consequences if appropriate treatment is not given promptly. The role of professional healthcare providers managing these individuals is to identify and treat infection as

Corresponding author:

Mohamad Adam Bujang

Biostatistics Unit,

Clinical Research Centre, Kuala Lumpur

$1^{\text {st }}$ Floor MMA House Jalan Pahang

50586 Wilayah Persekutuan Kuala Lumpur

03 - 40443060 (Office)

03 - 40443080 (Fax)

adam@crc.gov.my early as possible, and preventing complications. However, diagnosing infection in an ulcerated diabetic foot is not always straightforward. In diabetics, the host inflammatory response to injury or infection may be reduced because of impaired leukocyte function, vascular disease, and neuropathy. ${ }^{2}$ Diagnosing infection in diabetic foot ulcer is based on clinical signs and symptoms of inflammation. Properly culturing an infected lesion can disclose the pathogens and provide their antibiotic susceptibilities. ${ }^{3}$

The first line of treatment is usually started prior to knowing what organism is involved. Organisms were usually determined within a week by the pathologists after antibiotics have been started. Thus, the match of between the organisms and the antibiotics can be investigated. This study aimed to determine the most common organisms isolated in diabetic foot infections in Malaysia. By understanding this pattern, recommendations of the most suitable regime of antibiotics to be used as the first line of treatment can be proposed.

\section{MATERIALS AND METHODS}

A retrospective record review was conducted from the National Orthopaedic Registry Malaysia (NORM) database. Patients with diabetes mellitus type 2 who had foot infections, admitted to 18 government 
hospitals in Malaysia from 1st January 2008 until 31st December 2009 were recruited into the study. The authors received permission from the NORM Committee and have received ethical clearance from the Ethical Committee of the Ministry of Health Malaysia. Patients with information regarding organisms and treated antibiotics were included in the study. The guideline for appropriateness of antibiotics towards the organisms were based on the National Antibiotic Guideline $2008^{4}$ and Clinical Laboratory Standard Institute 2011 (40 $0^{\text {th }}$ Edition $)^{5}$.

The summary of the organism and antibiotic used is presented in Table I. Demographics data were obtained from patients' medical record, while the tissue specimens were obtained from biopsy, ulcer curettage, aspiration and wound swab. This study has been registered with the National Medical Research Register (NMRR-08-1349-2597).

\section{Statistical analysis}

Demographic data, types of antibiotics, types of organism and their appropriateness are tabulated for descriptive statistics such as in frequency (n) and percentage (\%). A chi-square test was used to analyze the association of each organism that received appropriate antibiotics, the antibiotics that used for an appropriate organism and the appropriateness of treatment and the growth status. All analyses were performed using SPSS version 18.0 (IBM Corp. Released 2010. IBM SPSS Statistics for Windows, Version 19.0. Armonk, NY: IBM Corp).

\section{RESULTS}

A total of 416 patients were included in the study. More than half $(54.6 \%)$ of them were female. The majority of patients were Malay (83.7\%) and in the age group of 50 years and above (71.9\%) (Table II). Out of 416 patients, $79.8 \%(332 / 416)$ of patients had single growth, $17.8 \%(74 / 416)$ had mix growth $(n=2)$ and $2.4 \%(10 / 416)$ of patients had multiple mix growth $(n>2)$. The most common organisms cultured are Proteus species (17.5\%), Klebsiella species (17.1\%), S. Aureus (17.9\%), E.coli (9.2\%), Haemolytic Streptococcus (8.0\%), Enterobacter species (6.7\%) and Pseudomonas Aeruginosa (8.6\%).

Table I: Summary of organism and suggested for antibiotic treatment for lower limb infection of diabetes patients

\begin{tabular}{|c|c|c|}
\hline \multirow{2}{*}{ Organism } & \multicolumn{2}{|c|}{ Suggested Treatment } \\
\hline & Antibiotic (Preferred) & Antibiotic (Alternative) \\
\hline 1. Anaerobic - Bacteroides spp & $\begin{array}{l}\text { Ampicillin PLUS } \\
\text { Gentamicin PLUS } \\
\text { Metronidazole }\end{array}$ & $\begin{array}{l}\text { Ampicillin/sulbactam OR } \\
\text { Amoxycillin/clavulanate OR } \\
\text { Piperacillin-tazobactam OR } \\
\text { Meropenem/ Imipenem }\end{array}$ \\
\hline $\begin{array}{l}\text { 2. Coagulase positive } \\
\text { Staphylococcus } \\
\text { - Staphylococcus aureus }\end{array}$ & Cloxacillin & $\begin{array}{l}\text { Erythromycin OR } \\
\text { Cefuroxime OR } \\
\text { Amoxycillin / Clavulanate } \\
\text { \# Clindamycin (if allergy to Penicillin) }\end{array}$ \\
\hline $\begin{array}{l}\text { 3. Enterobacteriaceae } \\
\text { - Enterobacter spp } \\
\text { - Klebsiella spp } \\
\text { - Proteus spp } \\
\text { - Serratia spp }\end{array}$ & $\begin{array}{l}\text { Amoxycillin / clavulanate OR } \\
\text { Cefuroxime }\end{array}$ & $\begin{array}{l}\text { Ampicillin / sulbactam OR } \\
\text { Piperacillin OR } \\
\text { Piperacillin / tazobactam OR } \\
\text { Meropenem/ Imipenem (severe / Multi re- } \\
\text { sistant organism) }\end{array}$ \\
\hline $\begin{array}{l}\text { 4. Pseudomonas spp } \\
\text { - Pseudomonas aeruginosa }\end{array}$ & $\begin{array}{l}\text { Ceftazidime OR } \\
\text { Cefepime OR } \\
\text { Piperacillin OR } \\
\text { Piperacillin / tazobactam OR } \\
\text { Ciprofloxacin }\end{array}$ & Meropenem/ Imipenem \\
\hline $\begin{array}{l}\text { 5. Streptococcus spp } \\
\text { - Enterococcus spp }\end{array}$ & Ampicillin & $\begin{array}{l}\text { Erythromycin OR } \\
\text { Cephalexin } \\
\text { If resistant to Penicillin : Vancomycin OR }\end{array}$ \\
\hline $\begin{array}{l}\text { - Beta hemolytic Streptococcus } \\
\text { (group A) } \\
\text { - Streptococcus viridans }\end{array}$ & $\begin{array}{l}\text { Benzylpenicillin PLUS } \\
\text { Clindamycin }\end{array}$ & $\begin{array}{l}\text { Ampicillin / sulbactam } \\
\text { \# Clindamycin (if allergy to Penicillin) }\end{array}$ \\
\hline 6. Acinetobacter spp & $\begin{array}{l}\text { Ampicillin / sulbactam OR } \\
\text { Cefoperazone / sulbactam }\end{array}$ & $\begin{array}{l}\text { Meropenem/ Imipenem OR } \\
\text { Ciprofloxacin PLUS Amikacin OR Ceftazidime }\end{array}$ \\
\hline
\end{tabular}


Table III shows the distribution of organisms and the appropriateness of antibiotics used. Many patients received appropriate antibiotics for organisms such as Serratia (100\%: $p=0.032)$, Proteus $(78.7 \%$ : $\mathrm{p}<0.001)$ and Klebsiella (74.7\%: $\mathrm{p}<0.001)$. Less were treated for Staphylococcus Aureus (22.0\%: $\mathrm{p}<0.001)$, E.coli (14.9\%: $\quad \mathrm{p}<0.001)$, Acinetobacter (12.9\%: $\mathrm{p}<0.001)$, Pseudomonas Aeruginosa (9.1\%: $\mathrm{p}<0.001$ ).

Table II: Distribution for demographic profile of respondent $(\mathrm{N}=416)$

\begin{tabular}{lll}
\hline Profile & & $\mathrm{n}(\%)$ \\
\hline \multirow{2}{*}{ Gender } & & \\
& Male & $189(45.4)$ \\
Race & Female & $227(54.6)$ \\
& Malay & $348(83.7)$ \\
& Chinese & $32(7.7)$ \\
& Indian & $33(7.9)$ \\
Age Group & $3(0.5)$ \\
& Others & \\
& $18-29$ & $8(1.9)$ \\
& $30-39$ & $20(4.8)$ \\
$40-49$ & $89(21.4)$ \\
$50-59$ & $150(36.1)$ \\
& $>60$ & $149(35.8)$ \\
\hline
\end{tabular}

Table III: Distribution of organisms and the organisms that received appropriate antibiotics

\begin{tabular}{|c|c|c|c|}
\hline Organism & $\bar{N}(\%)$ & $\%$ & P-value \\
\hline Proteus & $89(17.5)$ & $78.7(70 / 89)$ & $<0.001$ \\
\hline Klebsiella & $87(17.1)$ & $74.7(65 / 87)$ & $<0.001$ \\
\hline $\begin{array}{l}\text { Staphylococcus } \\
\text { aureus }\end{array}$ & $91(17.9)$ & $22.0(20 / 91)$ & $<0.001$ \\
\hline E.coli & $47(9.2)$ & $14.9(7 / 47)$ & $<0.001$ \\
\hline $\begin{array}{l}\text { Pseudomonas } \\
\text { aeruginosa }\end{array}$ & $44(8.6)$ & $9.1(4 / 44)$ & $<0.001$ \\
\hline Hemolyticstrep & $41(8.0)$ & $61.0(25 / 41)$ & 0.247 \\
\hline Enterobacter & $34(6.7)$ & $64.7(22 / 34)$ & 0.134 \\
\hline Acinetobacter & $31(6.1)$ & $12.9(4 / 31)$ & $<0.001$ \\
\hline Enterococcus & $19(3.7)$ & $57.9(11 / 19)$ & 0.624 \\
\hline Bacteroides spp & $15(2.9)$ & $60.0(9 / 15)$ & 0.549 \\
\hline Serratia & $5(1.0)$ & $100.0(5 / 5)$ & 0.032 \\
\hline $\begin{array}{l}\text { Streptococcus } \\
\text { viridian }\end{array}$ & $4(0.8)$ & $50.0(2 / 4)$ & 0.923 \\
\hline Bacteroides & $3(0.6)$ & $66.7(2 / 3)$ & 0.620 \\
\hline
\end{tabular}

Percentages were calculated based on number of appropriate antibiotics used/n $\times 100$
Table IV shows the association of the antibiotics that were used for appropriate organisms. The result was statistically significant $(p<0001)$. The most commonly used antibiotic was ampicillin/ sulbactam (67.5\%). All patients had been treated appropriately with ceftriaxone. More than half of patients received ampicillin (61.6\%), ciprofloxacin $(66.7 \%)$ and cefuroxime $(69.4 \%)$ appropriately. None of these patients was appropriately treated with metronidazole, cefoperazone and or fucidic acid. There was a pattern of association between appropriateness of antibiotics and the status of organisms' growth as shown in Figure 1. Result showed that more inappropriate antibiotics were prescribed for mix growth organism.

Table IV: Distribution of antibiotics and the antibiotics that were used for appropriate organism

\begin{tabular}{lrl}
\hline Antibiotics & $\mathrm{n}(\%)$ & \multicolumn{1}{c}{$\%$} \\
\hline $\begin{array}{l}\text { Ampicillin/ } \\
\text { Sulbactam }\end{array}$ & $281(67.5)$ & $61.6(173 / 281)$ \\
Cloxacillin & $41(9.9)$ & $31.7(13 / 41)$ \\
Cefuroxime & $36(8.7)$ & $69.4(25 / 36)$ \\
Metronidazole & $21(5.0)$ & $0.0(0 / 21)$ \\
Ceftazidime & $7(1.7)$ & $14.3(1 / 7)$ \\
Cefoperazone & $6(1.4)$ & $0.0(0 / 6)$ \\
Ampicillin & $5(1.2)$ & $20.0(1 / 5)$ \\
Ceftriaxone & $3(0.7)$ & $100.0(3 / 3)$ \\
Ciprofloxacin & $3(0.7)$ & $66.7(2 / 3)$ \\
Amoxicillin/ & $2(0.5)$ & $50.0(1 / 2)$ \\
Clavulanate & & \\
Fucidic acid & $2(0.5)$ & $0.0(0 / 2)$ \\
Piperacillin/ & $2(0.5)$ & $50.0(1 / 2)$ \\
Tazobactom & $7(1.4)$ & $14.3(1 / 7)$ \\
Others & & \\
\hline & & \\
\hline
\end{tabular}

The association was statistically significant with $\mathrm{p}$ - value $<0.001$. Percentages were calculated based on number of appropriate antibiotics used/n x 100 . 


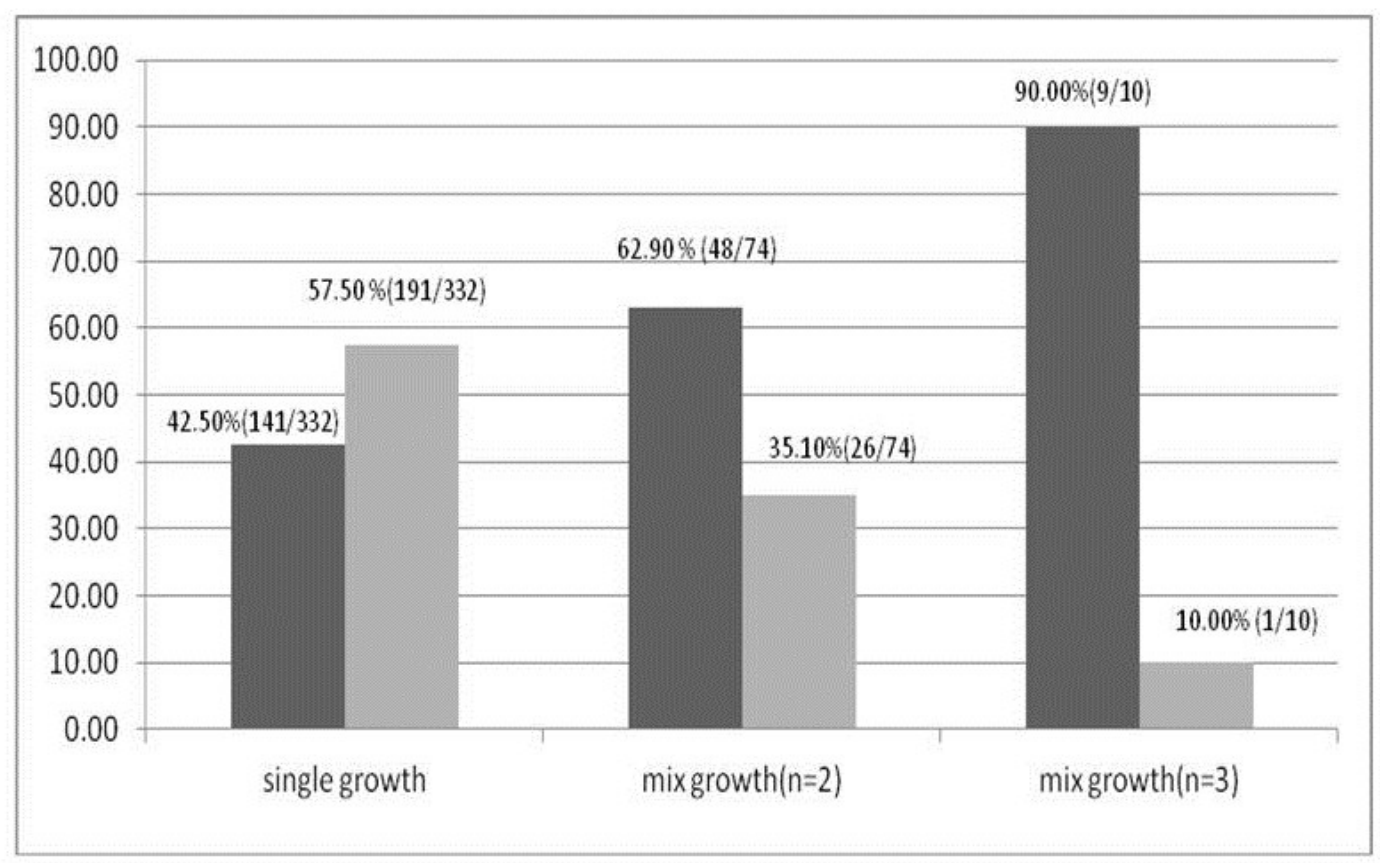

Figure 1. Result showed that more inappropriate antibiotics were prescribed for mix growth organism.

\section{DISCUSSION}

The aim of this study is to determine the most common organisms isolated in diabetic foot infection and to recommend the most suitable regime of antibiotics to be used as the first line of treatment. The most common organisms cultured in our study are Proteus sp (17.5\%), Klebsiella species (17.1\%) and Staphylococcus aureus (17.9\%). Anaerobic species (includes bacteroides) were only cultured in $3.5 \%$. This is because many specimens were not sent for anaerobic culture. Pseudomonas species was cultured in $8.6 \%$ of patients. Pseudomonas is the main cause of hospital-acquired infections especially in the long hospital stay patients.

Data on Methicillin Resistant Staphylococcus Aureus (MRSA) infection was not known, as we only take the specimen on the day of admission before antibiotics were started. More than $60 \%$ of anaerobic organisms were treated with appropriate antibiotics. The most common antibiotics given in our study were ampicillin / sulbactam (67.5\%), cloxacillin $(9.9 \%)$, cefuroxime $(8.7 \%)$ and metronidazole(5.0\%). From our study, we showed that the appropriate treatment for diabetic foot infection caused by $S$. aureus occurs in only $22.0 \%$ of patients. In order to improve the antibiotic appropriateness as our current antibiotic regimes, clinicians are recommended not to tackle the Staphyloccus infection. Therefore, our recommendation is to include cloxacillin in all diabetic foot infection to cover for the staphylococcus infection before the definitive culture received.
Study by Tentolouris et, al,..(1999) stated that Grampositive aerobic bacteria were the commonest micro -organism isolated (56.7\%) followed by Gramnegative aerobic bacteria and anaerobes $(29.8 \%$ and $13.5 \%$, respectively). Of the Gram-positive aerobes, $S$. aureus was found most frequently and $40 \%$ were MRSA. MRSA was isolated more commonly in patients treated with antibiotics prior to the swab compared to those who had not received antibiotics. $^{6}$

Aerobic gram-positive cocci are the major pathogens in diabetic foot infections. These may be the sole isolate(s) in acute uncomplicated infections, but they are usually accompanied by aerobic gramnegative bacilli or anaerobes in chronic or previously treated infections. Patients with mild infections can be treated as outpatients with oral antibiotics, but others require hospitalization and broad-spectrum parenteral antibiotics. ${ }^{7} \mathrm{~S}$. aureus was the most common isolate; being isolated in $38.4 \%$ of cases. Other organisms includes Pseudomonas aeruginosa $(17.5 \%)$, Proteus mirabilis $(18 \%)$, and anaerobic gram-negative organisms $(10.5 \%)$, mainly Bacteroides fragilis. Imipenem, meropenem, and cefepime are the most effective agents against gram -negative organisms. Vancomycin is the most effective against gram-positive organisms. ${ }^{8}$

Aerobic gram-positive cocci are the most important pathogens. In chronic, complex or previously treated wounds, concurrent infection with gram-negative bacilli and anaerobes may occur, resulting in polymicrobial infection. ${ }^{1}$ Aerobic gram-positive cocci (especially S. aureus) are the predominant 
pathogens in diabetic foot infections. Patients who have chronic wounds or who have recently received antibiotic therapy may also be infected with gramnegative rods, and those with foot ischemia or gangrene may have obligate anaerobic pathogens. ${ }^{9}$

Among aerobic pathogens, Enterobacteriaceae family (48\%), Staphylococcus species (18.2\%), Streptococcus spp (16.8\%) and Pseudomonas spp (17\%) were seen frequently. Among anaerobes Peptostreptococcus spp. and Clostridium spp. comprise of $69.4 \%$ of infection. Gram-negative anaerobes like Bacteroides spp. and Fusobacterium spp. were present in $30.6 \%{ }^{10}$ Therapy aimed solely at aerobic gram-positive cocci may be sufficient for mild-tomoderate infections in patients who have not recently received antibiotic therapy. Broad-spectrum empirical therapy is not routinely required but is indicated in severe infections, pending culture results and antibiotic susceptibility data.

Taken into consideration any recent antibiotic therapy and local antibiotic susceptibility data, especially the prevalence of MRSA or other resistant organisms. Definitive therapy should be based on both the culture results and susceptibility data and the clinical response to the empirical regimen. ${ }^{9}$ Antibiotic regimens are usually selected empirically initially, then modified if needed based on results of culture and sensitivity tests and the patient's clinical response. Initial therapy, especially in serious infections, may need to be broad-spectrum, but definitive therapy can often be more targeted. Severe infections usually require intravenous therapy initially, but milder cases can be treated with oral agents.

Therapy should nearly always be active against staphylococci and streptococci, with broaderspectrum agents indicated if Gram-negative or anaerobic organisms are likely. ${ }^{11} \mathrm{~S}$ aureus is the most common isolate in these infections. Increasing incidence of MRSA over the past two decades has further complicated antibiotic treatment. While chronic infections are often polymicrobial, many acute infections in patients not previously treated with antibiotics are caused by a single pathogen, usually a gram-positive coccus. ${ }^{9}$

Antibiotic therapy is necessary for virtually all infected wounds, but it is often insufficient without appropriate wound care. ${ }^{9}$ When culture and sensitivity results are available, specific or definitive therapy should be addressed. Changing to narrower spectrum agents is preferred but it is important to assess how the infection has been responding. If the lesion is healing and the patient is tolerating the empiric regimen there may be no reason to change, even if some or all of the isolated organisms are resistant to the agents is being used. On the other hand, if the infection is not responding, treatment should be changed to cover all the isolated organisms. If the infection is worsening despite the isolated organisms being susceptible to the chosen regimen, consider the need for surgery or the possibility that fastidious organisms were missed. ${ }^{11}$

\section{Study limitation}

This study has few limitations. The recruited subject might not cover all diabetes patients in Malaysia. However, these findings were derived from a multicentre study and relatively has large sample $(n=419)$. Previous studies showed that results derived from studies with sample size closed to 500 subjects or more are likely to have the same parameters as a particular population. ${ }^{12}$ In addition, not all sample culture was taken from tissue or aspirate. Some were taken using wound swab. Majority of the samples were obtained intraoperative as deep tissue specimen, however due to the nature as patient registry data, this study could not estimate the minority samples that were obtained from wound swab. Therefore, future research is suggested to emphasize on sample obtained from tissue.

\section{CONCLUSION}

The most common organisms cultured in this study are Proteus sp, Klebsiella sp. and S. aureus. The most common antibiotic usage is ampicillin/ sulbactam. Staphylococcus infection in diabetic foot is not properly treated in our study. This information may help the healthcare provider to understand the prescription pattern and serves as a guide on the most appropriate treatment for diabetes foot infections.

\section{ACKNOWLEDGEMENT}

The authors would like to acknowledge the Director General of the Ministry of Health for his support in our effort in the registry. They also like to thank Registry manager, Mr. Naren Kumar A/L Surendra and all the National Orthopaedic Registry of Malaysia (NORM) committee members in all hospital for contributed to the data collection.

\section{CONFLICT OF INTEREST}

We declare that we do not have any conflict of interest of this manuscript.

\section{REFERENCES}

1. Lipsky BA, Berendt AR. Principles and practice of antibiotic therapy of diabetic foot infections. Diabetes Metab Res Rev 2000; 16(S1):S42-S46.

2. Williams DT, Hilton JR, Harding KG. Diagnosing foot infection in diabetes. Clin Infect Dis 2004; 39(Suppl 2):S83-S86.

3. Armstrong DG \& Lipsky BA. Diabetic foot infections: stepwise medical and surgical management. Int Wound J 2004; 1(2):123-132.

4. National Antibiotic Guideline 2008, Ministry of Health, Malaysia [online]. Available at: http:// 
www.pharmacy.gov.my/aeimages//File/

National_Antibiotic_Guideline_2008_edit(2).

pdf = http://apps.who.int/medicinedocs/en/

m/abstract/Js17800en/. Accessed June, 2013.

5. Sanford JP, Gilbert DN et al. The Sandford guide to antimicrobial therapy 2010, 40th edition Antimicrobial Therapy, Inc. Sperryville, VA, USA [online]. Available at: www.sanfordguide.com. Accessed June, 2013.

6. Tentolouris N, Jude EB, Smirnof I, et al. Methicillin-resistant Staphylococcus aureus: an increasing problem in a diabetic foot clinic. Diabet Med 1999; 16(9): 767-71.

7. Lipsky BA, Pecoraro RE, Wheat LJ. The diabetic foot. Soft tissue and bone infection. Infect Dis Clin North Am 1990; 4(3):409-32.

8. Abdulrazak A, Bitar ZI, Al-Shamali AA, et al. Bacteriological study of diabetic foot infections. J Diabetes Complications 2005; 19 (3): 138-141.

9. Lipsky BA, Berendt AR, Deery $H G$, et al. Diagnosis and treatment of diabetic foot infections. Clin Infect Dis 2004; 39:885-910.

10. Viswanathan V, Jasmine JJ, Snehalatha C, et al. Prevalence of pathogens in diabetic foot infection in South Indian type 2 diabetic patients. J Assoc Physicians India 2002; 50:1013-6.

11. Lipsky BA. Evidence-based antibiotic therapy of diabetic foot infections. FEMS Immunol Med Microbiol 1999; 26(3-4): 267-276.

12. Bujang MA, Ghani PA, Zolkepali NA, et al. A comparison between convenience sampling versus systematic sampling in getting the true parameter in a population: explore from a clinical database: the Audit Diabetes Control Management (ADCM) registry in 2009. Statistics in Science, Business, and Engineering (ICSSBE), 2012 International Conference. 10-12 September 2012: p1-5. 